\title{
Modern water conservancy system in Guizhou
}

\author{
Zhang He-xi, Wang Yong-tao, Liu Liu, Lei Wei,Zhou Qin-hui
}

Water Resource Research Institute of Guizhou Province, Guizhou, China 550002

Keywords:The key points and innovations; The purpose and significance of building; Water conservancy reform and development; Construction effect

Abstract:Based on the achievements in construction of modern water conservancy project construction in Guizhou pilot area, the construction points and innovation, the purpose and significance of water conservancy construction, reform, effect are discussed, providing direction for the new agricultural water conservancy construction in our province.

\section{Introduction}

The traditional agricultural water conservancy project in our province was in a condition difficult to construct 、manage、maintain and charge for a long time, and it couldn't play a normal irrigation function ,too. The reason is: firstly, small-scale management under the land contract responsibility system doesn't adapt to large-scale operation nature demand of water conservancy and irrigation. Secondly, the fragmentary and unordered management of the land users doesn't fit the organization management of water conservancy facilities. Thirdly, the traditional management mode of small-scale water conservancy facilities whose property is nationalized is disconnected with the reality requires of rural grassroots organization management. Fourthly, the free concept of "Big-Pot Water" doesn't fit the scarcity and commodity attribute of water conservancy's "project water". Fifthly, the systemic and integrated input need by modern efficient agricultural garden construction doesn't fit their independent policy "fight along". In the end, agricultural water conservancy facilities were built by the state for a long time, and users don't want to manage. Besides, once the industrial structure change, and irrigation methods does not adapt, it will lead to a situation that engineering facilities are idle and benefit can't play. To resolve this problem, Since August 2014, Guizhou provincial water conservancy bureau has carried out 4 mountain modern conservancy pilot projects in Sinan、Xifeng、Huishui and Ziyun, which innovated the mechanism of agricultural water conservancy project, and realized a good situation for the integration of custody.

\section{Construction Key Points and Innovations}

\section{Construction Key Points}

\section{Construction Point}

(1) Project leading enterprises, large farmer-households or contractor are in strong demand and welcome of water conservancy facilities, and they agree the behavior to charge water-fee for the good operation of the project, they are also willing to pay for the water, so they can get considerable benefits from it.

(2) Enterprises and large farmer-households have built or promised to build part of the field facilities. The water facilities before the connectors are in principle invested by government, the other irrigation devices should be afforded by users, (including sprinkler irrigation 、 drip irrigation and micro-irrigation and so on), and these facilities should be built managed and employed by themselves, to develop a good situation that government and water users invest together and a new project construction model-ppp, to solve the risk of government's invest and manage.

\section{Construct to Reflect" Two" Modernization}

\section{(1) Modernization of Water Conservancy Project Technology}

Domestic leading efficient water-saving irrigation technology, automation and information technology, wireless data/video transition technology and integration of water and fertilizer 
technology are the core of the project technology. The high standard construction contains serious of synthetical factors, such as meteorological watch, soil moisture content watch, integration of water and fertilizer, drip irrigation, microspray irrigation, remote control of pipeline flow, automation on and off and remote control of water pump and scientific experiment. It saves not only water and energy but also fertilizer and labor force.

\section{(2) Modernization of Management Systems and Mechanisms}

Promote the villagers autonomous management through reforming management rights enlivening the operation rights and expanding the participation rights. Water use cooperative association (water user association) played an important role in the whole project process; they could manage themselves, and realize a participatory autonomy management mode. They also encouraged beneficiary taking an active part in constructing and managing the project, gave advice to the designing scheme, especially harmonized the water conservancy irrigation and drainage engineering layout and covering solution, defused the former problem that hard to built and harmonize. The agricultural water price is determined by water use association according to the water-price accounting, democratic consultation, independent pricing, governmental recording.

\section{Strictly Carry Out "Four System" Requirements}

Strictly carry out biding system, set management units and construction units apart. It must form a formal legal person unit for project construction; the unit should be approved by the county government. Water conservancy bureau cannot be the project legal person. The four system solved the disadvantages of "both athletes and referees" before, guarded against the risk of corruption; strictly carry out the construction supervision system, investment, progress and quality control are guaranteed.

\section{Innovations}

As an innovation of agricultural water conservancy project in our province, it mainly displays in the innovative thought, water price forming mechanism, water fee allocation mechanism, and the mode that responsibility, right and benefit peer grading management.

\section{Innovations in Thought}

Firstly, there is a new thinking way that problem and demand oriented. To solve problems, and realize the sustainable development of agricultural water conservancy, water conservancy bureau put forward the new idea of developing modern water conservancy in Guizhou mountain area by taking the reversed methodology about problems and demands, developing the water conservancy as the commander.

Secondly, the innovated thinking "building mechanism first and then project" exploits a new path of reform of the water conservancy construction management system. At the early stage of the project construction, an "integration of custody" reform plan should be formulated first. Project construction and practice of the management mechanism should also propel synchronously, after completing the project, the reform office should actively supervise and guide, implement the mechanism construction.

\section{Formation Mechanism of Water Price}

Formulate principles: compensation cost, reasonable profits, high quality and equal price, fair burden; integration of valuation according to table and levy according to acreage; total water control and quota management; two-part system-basic usage and meterage, exceeding quota progressive surcharges; different industry water price; user participation.

Approval for water price: non-agricultural water supply price is approved on the basis of water price in accordance with calculation price adjustment provisions for the administration by the commodity price departments; agricultural water price is determined by water user association according to the water-price accounting, democratic consultation, independent pricing, governmental recording; agricultural water quota is determined according to the water demand of crop species areas which are reported to water management unit at the beginning of each year by the water user association.

\section{Allocation mechanism of water fee}

"Pay in advance, then supply water, finally clear according to the reality water consumption ", Water users report their water plan to water user association and prepay for it, then the association will notify the control system manager to supply water to users as planned. Water fee income of the association will be carried out a reasonable allocation plan in proportion according to the actual 
engineering. Take the modern water conservancy experimental area in Huishui Lianjing for example: They executed a "4:3:2:1" expenditure allocation plan, namely, 40\% of the income are used for daily maintenance and electricity costs; $30 \%$ for manager's remuneration; $20 \%$ for depreciation, this part will be the special deposit as the development fund of water user association and maintenance funds of the water conservancy project, it is mainly used for overhaul repair of water supply equipment and expanding of the water supply scope; the rest $10 \%$ for the development of village collective, this part is used for public undertakings of village collective, and solve the problem of "empty villages".

\section{Equal classification model of duty 、right and benefit}

By reforming management, it overall formed a classification model which integrated specialization and socialization: "water management unit + water user association + water users". Water management unit takes charge for the management and protection from the main water supply net to the high pool of water user association, the association is responsible for the management and protection from its high pool to water users' water connectors. And users take charge for the field irrigation facilities.

\section{Unified planning, unified construction}

Firstly, it is combined with urban construction. For example, the modern water conservancy in Sinan Tangtou combined the modern pilot area project with the construction of provincial demonstration town. It solved the drinking water safety of 28 thousands of people lived in Tangtou and the neighborhood. It also solved the problem of the town drainage and sewage treatment, it provided water conservancy support and assurance for Tangtou to become the one hundreds of demonstration small-town. Secondly, it is combined with park construction. The modern pilot area in Tangtou lies in the core region of its modern agricultural demonstration area. There is domestic leading efficient water-saving irrigation system with automation and information. It realized integration of water and fertilizer and remote automatic control. Thirdly, it was combined with urban flood control and drainage. It solved the problem flood control and waterlogging drainage of Guanzhong dam in Tangtou. Fourthly, it was combined with tourism development. The modern pilot area project in Tangtou was built combined with the modern agricultural demonstration area: 3 a-class tourist scenic area. It efficiently combined with the agricultural sightseeing tourism projects, completed a sample combined garden tourism with the modern water conservancy which is livable and suitable for tourism. It also provided a strong water conservancy support for the development of modern agricultural demonstration area tourism.

\section{The Purpose and Significance of Construction}

\section{Purpose of Construction}

Take the core area of modern and efficient agricultural demonstration area as the "target area", to establish a modern water conservancy irrigation system with modern, efficient water saving technology and automation, information technology, form a multi-sector and multi-channel fund integration means and a passive invest means that raise fund by enterprises (large) and professional cooperatives; Complete a level-to-level administration system which has clear property rights and functions, well-defined rights and responsibility, and effective operation; Complete the combination of specialization and socialization management maintenance. Form a reasonable water price mechanism and water fee collection system; Form an effective talent introduction, training mechanism; Establish an effective supervision system; Implement water ecological civilization construction which takes water safety as the core.

\section{Significance of Construction}

Prior to carry and try aim at carrier, the high standards modern water conservancy pilot construction ship in Guizhou mountain area sets sail. Modern efficient agricultural demonstration garden provides a "carrier" for modern water conservancy pilot construction in the mountain area, it mainly shows as follows : firstly, large enterprises and users realize the agricultural scale and organizational management through the flow of a large number of cultivated land, to provide a essential space for modern water conservancy layout; Secondly, "water conservancy is the lifeblood of agriculture," the desire for water conservancy facilities of these agricultural economic service organizations is also their essential requirements; Thirdly, flood control and drainage facilities are 
completed, water conservancy irrigation system is extended to the fields, and the agricultural economy service organizations can solve the "lifeline" anxiety only need a small amount of investment to construct field terminal irrigation facilities, realizing the maximization of the long-term economic benefits, so it can form a "win-win" effect, show more the shape of the PPP mode.

\section{Water Conservancy Reform}

Promote the property system reform of small rural water conservancy Project. Give those properties easy to manage to villager group or township, such as small pump station, small pool and irrigation pipe (canal), form village collective fixed assets; it can solve the "empty village" problem that rural collective economic organizations with no real assets, lay a foundation for the next water conservancy construction investment and financing work. Meanwhile, form a positive momentum "my things, my duty". Form a classification model which combines specialization and socialization "water management unit + water user association + water users", realize the target "integration of custody" and protect water use water.

\section{Construction Effect}

\section{Direct Benefits}

At present, four pilot areas are taking time to make summary of experiences, formed a batch of propgable and repeatable experiences and agricultural development model. After the construction of four pilot areas: Huishui Liangjiang Ziyun Huohua、 SinanTangtou and Xifeng Grap vally, the exploring way of modern water conservancy in Guizhou mountain area which is suitable the new situation gets an obvious achievement, mainly embodied as follows:

(1) Furthest played a fundamental role in the water conservancy facilities, not only solved the efficient water-saving irrigation of agricultural garden and modern control demand, also combined with water supply demand of the one hundreds of demonstration small towns (such as solved the origin water problems of 20 thousands of people's water use in their development in Sinan Tangtou), also improved the standard of water supply of these pilot area (such as ensured water supply of the development of rural tourism in Xifeng Grape valley).

(2) Solved the problem-- flood control and drainage of pilot areas, and improved the construction of ecological civilization. HuiShui Lianjiang pilot area has solved the waterlogging and underground waterlogging disaster that is traditionally looking forward to solving by the masses, increased the drainage standard to once every 10 years. Sinan Tangtou pilot area has solved the flood and waterlogging disaster, and changed the small flooded valley into ecological corridor and hydrophilic channel, made it an ecological wetland park which is suitable for rural tourism. Become a model that completes synchronously water conservancy project and construction of ecological civilization.

\section{Indirect Benefits}

Chain link 1: solved the problem that agricultural economic organizations must but lack of one-time invest to large water conservancy, enhanced its determine to speed up the construction of agriculture garden and long-term business. The most direct expression is the flow speed of the cultivated land has enhanced, and farmers achieved long-term stable income through farmland circulation. The masses can work nearby, also take care of the family, both raised children, and support the old man, lived a well-off life that income does not decrease and family harmony.

Chain link 2: agricultural economic service organization can obtain efficient water-saving irrigation with automation and informatizaion only through the construction of field water terminal. And it is one of the water user association board member, can directly participate in the formulation of water price, its rights and interests can get sufficient guarantee.

\section{Acknowledgements}

This work was financially supported by the Innovation Capability Special Fund in Guizhou Province Science and Technology Plan Project" Research on the AllocationWay of the Water 
Conservancy on the central of Qian Based on the Pre-market Model (Qian Kehe, major project word number [2012]6013-6-2), Guizhou Provincial Water Conservancy Bureau Scientific Project" Research on Big-scale Irrigation District Reconstruction and the Benefit Evaluation of Water-saving Reform "(KT201306).

\section{References}

[1] Chen lei. To fully implement the central rural work conference spirit to promote reform and development new span of water conservancy [J]. China Water Resources, 2011.1:2-4.

[2] To fully implement the central major decision deployment efforts to create a new situation of water conservancy reform and development [J]. China Water Resources, 2014.1:2-3.

[3] The guidance of the ministry of water resources to further the reform of water conservancy [J]. China Water Resources, 2014.3:1-5.

[4] Yuanxin Wang, Qiting Zuo. Reform and development strategic thought during the new period of our country and research of trend analysis [J] Water Resources Development Research, 2013.12:47-49.

[5] Along the water conservancy modernization with Chinese characteristics to promote reform and development new span of water conservancy. [J].Truth Seeking. 2011.6:17-18. 